\title{
ACTIVATION AND SUPPRESSION OF FIBROBLAST FUNCTION
}

\author{
P. T. KHAW ${ }^{1,2,3}$, N. L. OCCLESTON ${ }^{1,3}$, G. SCHULTZ ${ }^{2,3}$, I. GRIERSON ${ }^{1,4}$, M. B. SHERWOOD ${ }^{2}$ \\ and G. LARKIN ${ }^{1}$ \\ London
}

\begin{abstract}
SUMMARY
The fibroblast is the central player in the wound repair and scarring processes that occur in the anterior segment of the eye. Glaucoma filtration surgery is the ultimate example of the importance of the wound healing process, as this process is the major determinant of the success of this procedure. We highlight the role of the fibroblast, and discuss some of the growth factors stimulating fibroblast proliferation, migration and extracellular matrix production in the wound environment. We also review current methods of suppressing fibroblast proliferation, the new concepts that have arisen from laboratory studies, and future directions of investigation and treatment.

The processes involved in tissue repair play a critical role in either the pathogenesis or failure of treatment of most of the major blinding or visually disabling conditions in the world today. The biological processes that result in scarring account for a great deal of visual morbidity. In this review we use glaucoma filtration surgery as an example of the importance of scarring, as a model of the scarring process after ocular surgery, and also highlight the role of the fibroblast, the factors that may activate the fibroblast, and the effects of methods used to suppress fibroblast function.
\end{abstract}

\section{GLAUCOMA FILTRATION SURGERY: AN EXAMPLE OF THE IMPORTANCE OF THE SCARRING PROCESS}

The glaucomas are a group of disorders characterised by optic nerve head damage, visual field loss and an intraocular pressure sufficiently raised to affect function of the

From: International Collaborative Wound Research Group: ' Institute of Ophthalmology/Moorfields Eye Hospital, London, UK; ${ }^{2}$ Institute for Wound Research, University of Florida, USA; ${ }^{3}$ Phoenix Department Plastic Surgery, University College, London, UK; ${ }^{4}$ Department of Ophthalmology, University of Liverpool, UK.

Correspondence to: Mr Peng T. Khaw, MRCP, FRCS, FRCOphth, Consultant Ophthalmic Surgeon, Glaucoma Unit and Wound Healing Group, Moorfields Eye Hospital and Institute of Ophthalmology, City Road, London EC1V 2PD, UK.

Eye (1994) 8, 188-195 C 1994 Royal College of Ophthalmologists optic nerve head. Glaucoma is not a single disease process but rather a large group of diseases, which have in common damage to the optic nerve head. This group of diseases will soon be the second commonest cause of blindness in the world behind cataracts, affecting people in both developed and developing countries. ${ }^{1.2}$ Unlike cataracts, the blindness from glaucoma is essentially irreversible. Although many theories for the pathogenesis of optic nerve damage have been postulated, the major risk factor for glaucomatous optic nerve damage is the level of intraocular pressure. The higher the intraocular pressure, the greater the risk of optic nerve damage. ${ }^{3,4}$ Most treatment is aimed at reducing the intraocular pressure.

There are three main categories of treatment: medicine, laser or surgery. In recent years evidence has been accumulating that surgery is superior to either laser or medical treatment in lowering the intraocular pressure ${ }^{5}$ and preserving vision..$^{6-9}$ In addition, successful surgery results in a better quality of life for patients compared with medical treatment, ${ }^{10}$ and the use of topical medication (eyedrops) increases the chance of subsequent surgical failure. ${ }^{11}$ Furthermore, in many developing countries of the world, surgery is the only practical treatment to prevent blindness from glaucoma.

Glaucoma filtration surgery involves the creation of a new drainage channel for the aqueous humour to flow out of the eye and thus lower intraocular pressure. The commonest form of the procedure ${ }^{12}$ involves making an incision in the conjunctiva, dissecting open the subconjunctival space and making a trapdoor incision in the sclera up to the junction between the cornea and the sclera. The eye is entered and a block of corneoscleral tissue removed to create a new channel for aqueous outflow, and the trapdoor sutured down to create a valve mechanism. The conjunctival incision is then closed and the aqueous allowed to flow out under the conjunctiva. The aqueous may then flow away subconjunctivally, through aqueous veins, through lymphatics channels or transconjunctivally. ${ }^{13}$

The successful lowering of intraocular pressure after fil- 
tering surgery relies heavily on the nature of the healing response following the surgery. It is variations in this healing response that result in the majority of failed filtering procedures. Several risk factors may increase the chance of filtration surgery failing and these are shown in Table I. The reasons for the increased scarring response in patients with these risk factors are still unclear. Furthermore, just as important as absolute failure is suboptimal lowering of the intraocular pressure. There is evidence that the greater pressure lowering associated with surgery is associated with a better visual prognosis. ${ }^{9}$ The healing response is the major determinant of the final intraocular pressure. In terms of the entire glaucoma population undergoing surgery, this is probably a much more important problem epidemiologically than the far smaller but highly visible group that completely fail surgery. Thus the healing response is the single most important modifiable factor determining outcome in every patient undergoing glaucoma filtration surgery.

\section{CELLULAR EVENTS AFTER GLAUCOMA FILTRATION SURGERY AND THE ROLE OF THE FIBROBLAST}

The sequence of events following glaucoma filtering surgery can be illustrated in a simplified diagrammatic form (Table II), although some of the events obviously occur concurrently. When incisions are made in the conjunctiva and sclera, connective tissue and blood vessels are damaged. This results in the release of blood cells and plasma proteins into the damaged site. The clotting system is activated and clot forms around the damaged areas. This is similar to the events that occur after cutaneous or other wounding.

However, the glaucoma filtration surgical site differs in one fundamental aspect: it is bathed by aqueous humour emerging from the eye through the newly created fistula. This aqueous humour and its contents can have very significanteffects on the healing response after glaucoma surgery. There have been suggestions that the aqueous contains an inhibitory factor or factors, ${ }^{27,28}$ and aqueous clearly modulates the wound as dissected conjunctiva normally scars down rapidly to the episclera without aqueous. However, aqueous also has stimulatory effects on fibroblasts in vitro $^{29,30}$ and in vivo. A particularly good example is the aggressive scarring seen after filtration surgery in patients with new vessel formation within the eye. In this situation the aqueous humour, which is presumably full of stimulating factors, invariably induces rapid scarring and subsequent surgical failure. Even in a relatively undiseased eye (e.g. cataract extraction), when the eye is entered some

Table I. Risk factors for failure of glaucoma filtration surgery

Topical medications $>1$ year $^{11,14,15}$

Age $<40$ years $^{16-20}$

Afro-Caribbean ${ }^{21-24}$

Previous failed filter ${ }^{25}$

Previous cataract surgery ${ }^{25}$

Uveitis $^{26}$

Anterior segment neovascularisation ${ }^{26}$

Aphakia/pseudophakia ${ }^{25}$ degree of blood-aqueous barrier breakdown occurs, ${ }^{31-33}$ bringing in serum factors to the wound site.

Polymorphonuclear cells move into the wound area followed by lymphocytes and macrophages. Fibroblasts then begin to migrate towards sites of damage. As they migrate they probably cause wound contraction. The tractional forces exerted by moving fibroblasts have been elegantly demonstrated by Harris et al.$^{34}$ who seeded fibroblasts onto ultrathin polymerised silicone. We have been using this model to investigate fibroblast-mediated wound contraction; the forces generated by the moving fibroblasts are clearly seen in Fig. 1. The fibroblasts also begin to proliferate, which is necessary to generate sufficient numbers of cells to carry out the various wound-healing processes in a relatively short time. This process peaks within the first 2 weeks after experimental glaucoma filtration surgery, ${ }^{35-37}$ which is similar to cutaneous wounding.

Fibroblasts secrete fibronectin, glycosaminoglycans and

Table II. Sequence of events in wound healing and potential areas of modification after glaucoma filtering surgery (simplified: events and agents have overlapping time duration and action)

\begin{tabular}{|c|c|}
\hline Event & Possible areas of modulation \\
\hline $\begin{array}{l}\text { Conjunctival/episcleral/scleral } \\
\text { incisions }\end{array}$ & $\begin{array}{l}\text { Minimal trauma } \\
\text { Less invasive surgical techniques }\end{array}$ \\
\hline $\begin{array}{l}\text { Damage to connective tissue } \\
\text { Release of plasma proteins and } \\
\text { blood } \\
\text { Activation of clotting and com- } \\
\text { plement } \\
\text { Fibrin/fibronectin/blood cell clot } \\
\text { Release of growth factors from } \\
\text { blood }\end{array}$ & $\begin{array}{l}\text { Haemostasis } \\
\text { Agents preventing/ } \\
\text { removing fibrin (e.g. heparin, } \\
\text { tissue plasminogen activator) } \\
\text { Antagonists to growth factor } \\
\text { production, growth factor } \\
\text { activation (e.g. antisense } \\
\text { oligonucleotides), antibodies to } \\
\text { growth factors or receptors }\end{array}$ \\
\hline
\end{tabular}

Aqueous released from eye Breakdown of blood-aqueous barrier

Release of growth factors into Blood-aqueous barrier stabilising agents (e.g. non-steroidal antiinflammatory agents)

aqueous

Aqueous begins to flow through wound

Antagonists to growth factors

Migration and proliferation of polymorphonuclear neutrophil cells, macrophages and lymphocytes

Migration and proliferation of fibroblasts

Wound contraction $\downarrow$

Fibroblast synthesis of tropocollagen,

glycosaminoglycans and fibronectin

Collagen cross-linking and modification

Blood vessel endothelial migration and proliferation

Continued collagen synthesis Capillary resorption and disappearance of fibroblasts $\downarrow$

Fibrous subconjunctival scar
Anti-inflammatory agents (e.g. steroids)

Antiproliferative agents (e.g.

5-fluorouracil)

Antiproliferative agents

Anticontraction agents (e.g. taxol)

Anticross-linking agents (e.g. beta-aminopropionitrile)

Inhibitors of angiogenesis 


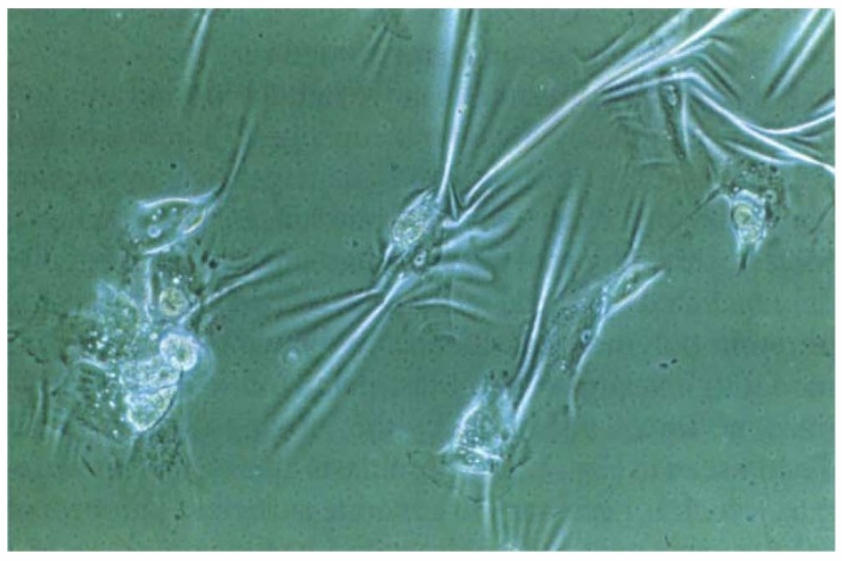

Fig. 1. Human Tenon's capsule fibroblasts seeded onto polymerised silicone sheets. As the fibroblasts move and migrate they create marked surface tractional forces.

tropocollagen which is then enzymatically cross-linked to form collagen. Collagen is a major component of the wound matrix and is a prominent feature of experimental filtering surgery failure in the rabbit and monkey. ${ }^{36,38}$ Many fibroblasts in the failing blebs of rabbits have cytoplasm rich in endoplasmic reticulum, with some distended cisternae. This appearance is consistent with an actively metabolising cell undergoing transcription. ${ }^{36}$ Collagen accumulation is also a prominent feature of failing blebs in man. ${ }^{39}$

This connective tissue is then remodelled continuously for several months ${ }^{40}$ with continued synthesis and breakdown of the extracellular matrix. Eventually most of the active cellular processes cease and the final result is subconjunctival scar. Successful filtering surgery is usually associated with a subconjunctival accumulation of aqueous humour, or a 'bleb' (Fig. 2). Failed filtration surgery is associated with a dense scar in the subconjunctival space which closes this potential space and prevents aqueous flow. It is obstruction by scarring at the episcleral levels rather than the fistula itself which is the main reason for failure. The process of healing and the scarring response can be modulated at various points in the process, and these are represented in Table II. However, most of the efforts to suppress scarring have concentrated on the fibroblast cell,

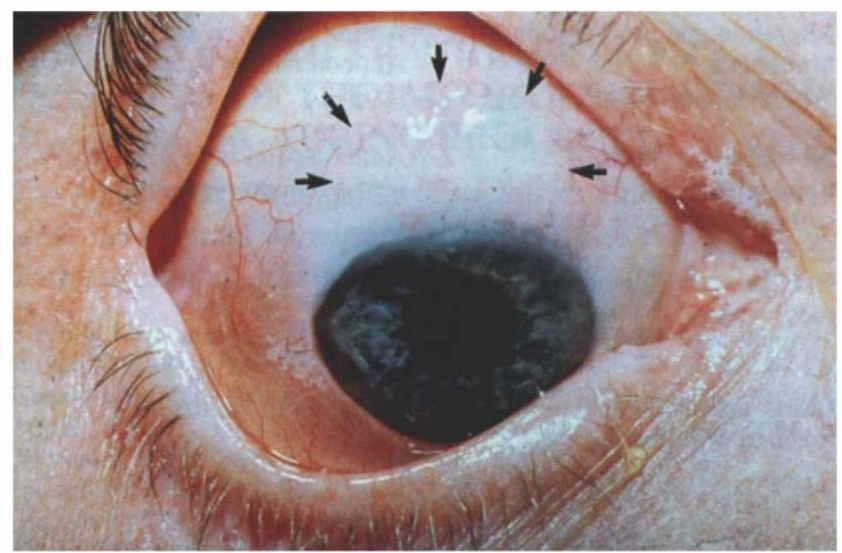

Fig. 2. A drainage bleb after glaucoma filtration surgery: collection of aqueous humour draining out of the eye under the conjunctiva. The edges of the bleb are marked with arrows. which is the central cell of the scarring process. Filtration surgery most commonly fails because of the build up of extracellular matrix, in particular collagen which obstructs the flow of aqueous. Without the fibroblast cell this failure would not occur.

\section{ACTIVATION AND STIMULATION OF THE FIBROBLAST}

Normally, the fibroblast exists within the subconjunctival connective tissue as a quiescent undifferentiated mesenchymal cell, the fibrocyte. This cell is found in low numbers throughout connective tissue. The fibrocyte converts to the active fibroblast capable of carrying out the various cellular functions responsible for wound healing when stimulated by various factors in the environment. For instance, factors which are known to stimulate fibroblast migration are the complement component $\mathrm{C} 5 \mathrm{a},{ }^{41}$ growth factors such as platelet-derived growth factor, transforming growth factor and fibroblast growth factor, ${ }^{42}$ elastin and collagen fragments, ${ }^{43,44}$ leukotriene, and fibronectin. ${ }^{45}$ These factors are derived from damaged tissue, blood, inflammatory cells such as macrophages, lymphocytes and macrophages, and from the fibroblasts themselves. In the aqueous itself there are factors known to stimulate fibroblasts, and these are listed in Table III. The relative roles of these growth factors in healing after wounding of the anterior segment of the eye are unclear.

We previously investigated the role of several growth factors in the migration of corneal fibroblasts ${ }^{46}$ and have more recently studied the effects of different concentrations $\left(10^{-7}\right.$ to $\left.10^{-14} \mathrm{mM}\right)$ of various growth factors including epidermal growth factor (EGF), basic fibroblast growth factor (bFGF), transforming growth factor beta-1 (TGF- $\beta 1$ ) and insulin-like growth factor 1 (IGF-1) on the migration, collagen synthesis and proliferation of human Tenon's capsule fibroblasts. We found that all four growth factors stimulated proliferation, migration and collagen production to some degree, but that TGF- $\beta 1$ stimulated proliferation at much lower concentrations than the other growth factors. In addition, TGF- $\beta 1$ also stimulated much more collagen production than EGF and bFGF; it is of interest, though, that IGF-1 also stimulated the same amount of collagen production as TGF- $\beta 1$, albeit at a higher concentration. These results suggest that targeting specific growth factors, in particular the TGF- $\beta$ family, may be a reasonable approach to preventing post-operative scarring in the eye. There is already evidence that modulating the profile of the TGF- $\beta$ family after cutaneous wounding may reduce scarring. ${ }^{47}$

Table III. Some stimulatory factors in the aqueous humour

Fibroblast growth factor

Epidermal growth factor ${ }^{\mathrm{a}}$

Transforming growth factor beta- 1 and beta- 2

Insulin-like growth factor 1

Fibronectin

Transferrin

Interleukin 6

${ }^{\mathrm{a} C}$ Controversial 
Table IV. Examples of some agents used to modulate ocular fibroblast function (some have more than one action)

\begin{tabular}{l} 
Anticytoskeletal \\
Colchicine \\
Cytochalasin b \\
Taxol \\
Nocodazole \\
Vincristine \\
Vinblastine \\
Antiproliferatives \\
Radiation \\
Doxorubicin \\
Bleomycin \\
Chlorambucil \\
Cytosine arabinoside \\
5-Fluorodeoxyuridine \\
5-Fluorouracil \\
Methotrexate \\
Mitomycin C \\
Gamma interferon \\
Anti-transferrin receptor monoclonal antibody conjugated to a \\
$\quad$ cellular poison, ricin \\
Immunosuppressives/anti-inflammatories \\
Prednisolone \\
Dexamethasone \\
Triamcinolone \\
Indomethacin \\
Meclofenamate sodium \\
Cyclosporin \\
Diphenhydramine \\
\hline
\end{tabular}

\section{MODULATION/SUPPRESSION OF FIBROBLAST FUNCTION}

A great deal of research has been carried out on agents which directly or indirectly modulate various aspects of fibroblast function (Table IV). Attempts have been made to target specific cell functions such as migration. Examples are colchicine, cytochalasin B and particularly taxol (which all affect the cytoskeleton of the cell), which were all shown to inhibit the migration of fibroblasts to rabbit aqueous humour. ${ }^{48}$ Taxol has been shown to prolong survival of filtration surgery in an aggressive model of filtration surgery. ${ }^{49}$ Another example is the use of lathyrogenic agents such as beta-aminopropionitrile, which prevents collagen cross-linking by inhibiting the enzyme lysyl oxidase. ${ }^{50}$ There is experimental and clinical evidence that this may work. ${ }^{51-53}$ However, many of these 'specific' agents have effects on other fibroblast functions: for instance taxol also inhibits cell proliferation and BAPN may also have antiinflammatory effects. ${ }^{54}$ Most of the work aimed at inhibiting scarring after glaucoma filtration surgery has concentrated on the inhibition of proliferation of ocular fibroblasts,

Table V. Theoretical implications of the concept of long-term, titratable, focal tissue suppression of fibroblast function

Simultaneous corneal surgery without inhibition of healing

Titration of the final intraocular.pressure by changing agents, concentration and area treated

Creation of more diffuse thicker blebs (theoretically safer) by changing agents, concentration and area treated

Positioning of thin drainage areas in the fornix away from vulnerable areas such as limbus

Preoperative use of these agents may be possible

Appropriate treatment to maximise anti-scarring effect and minimise complications if individual healing responses are better understood mainly on the premise that if there are inadequate numbers of cells, significant scarring cannot occur. However, it must be borne in mind that these agents clearly have effects on other aspects of fibroblast function.

Blumenkranz and colleagues ${ }^{55.56}$ established that various antiproliferative drugs, in particular 5-fluorouracil, inhibited the proliferation of fibroblasts during a period of continuous drug exposure in cell culture and prevented epiretinal scarring in the eye in an animal model. Stimulated by this initial research, a regimen involving subconjunctival injections of 5-fluorouracil was developed at Miami culminating in the multicentre 5-fluorouracil filtering surgery trial..$^{25}$ Many studies have also been carried out investigating the effects of 5-fluorouracil and many other antiproliferative agents on ocular fibroblasts in culture in an attempt to find an optimal agent, ${ }^{57-64}$ and also to develop an optimal delivery system that does not require multiple injections..$^{49,65-70}$ However, Chen and colleagues ${ }^{71.72}$ had been using single applications of another anti-proliferative agent, mitomycin- $\mathrm{C}$, for more than a decade, initially largely unnoticed. The use of this regimen has seen an exponential increase in popularity over the last few years because of the ease of application and effectiveness.

One of the reasons for the initial reluctance to use Chen's regimen was the lack of knowledge as to how a single application of these agents could suppress fibroblast proliferation adequately over the period of several weeks, during the period of maximal fibroblast proliferation. Our group has shown that several antiproliferative agents have longterm effects on the proliferation of ocular fibroblasts, even when the time of exposure is as short as 5 minutes. ${ }^{73.74}$ Given the appropriate concentration and agent, effective suppression of proliferation can be achieved for periods of up to 36 days without significant cell death. ${ }^{73,75}$ To our surprise, this long-term suppression also occurred with 5-fluorouracil, as the drug's inhibitory action on DNA synthesis through thymidylate synthetase should have been rapidly reversible. However, 5-fluorouracil, has, like all other drugs, secondary actions including interference with RNA synthesis, and these may explain the longer-term actions.

We have subsequently shown that this long-term suppression of proliferation occurs in an in vivo experimental model of glaucoma filtration surgery and appears to be titratable in terms of length of action. ${ }^{76.77}$ It is also focal in that only the fibroblasts in the treated areas are affected. ${ }^{78.79}$ The fact that this suppression of fibroblast proliferation is focal is very important clinically, and the theoretical implications are shown in Table V. Fibroblasts are not derived from the blood as was previously thought, but are derived from a local population of fibrocytes. Therefore recovery of local tissue healing due to fibroblasts can only occur if the local tissue fibroblasts recover from the focal treatment or if there is migration of fibroblasts into the area.

However, just as important as the effect on the cells themselves is the length and degree of stimulation present in the aqueous and the wound area. This stimulation can modify the overall profile of healing despite fibroblast modulation with the same treatment. A simplified model of 


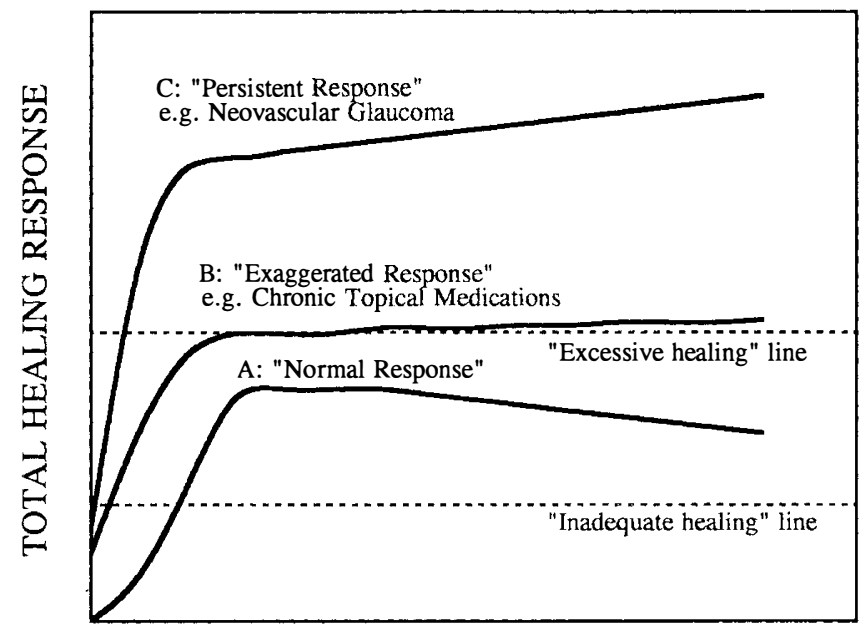

TIME AFTER INJURY

(a)

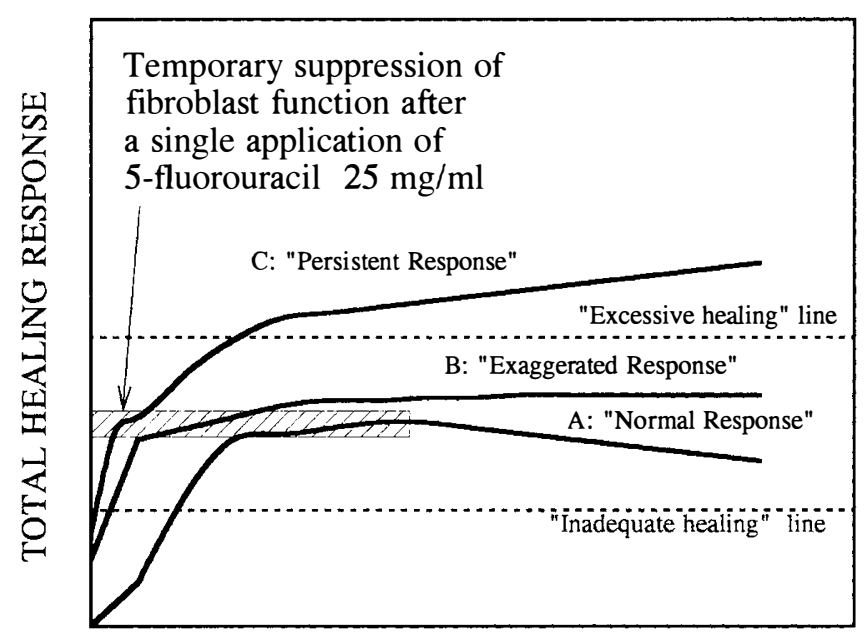

TIME AFTER INJURY

(b)

this concept is shown in Fig. 3. Essentially, this model represents three different profiles of healing, combined with a theoretical 'excessive healing' threshold line, which if crossed results in surgical failure. If excessive modulation is achieved, a theoretical 'inadequate healing' line is crossed and complications due to poor healing occur. The theoretical effects of a shorter-term inhibition (5-fluorouracil) and a longer-term inhibition (mitomycin-C) on these different healing profiles is shown. The inhibitory effect of mitomycin- $C$ has been placed below the 'inadequate healing' line as we now have good in vivo ${ }^{73}$ and in vitro ${ }^{80}$ evidence that part of the effect of mitomycin- $C$ at this concentration is due to actual cytotoxicity, while the remaining cells are growth arrested. Therefore, although we know we can adequately suppress fibroblast proliferation in a relatively titratable manner with practical singleapplication treatments, we still need to know more about the individual healing responses, and what functions the suppressed fibroblast is able to carry out under these conditions.

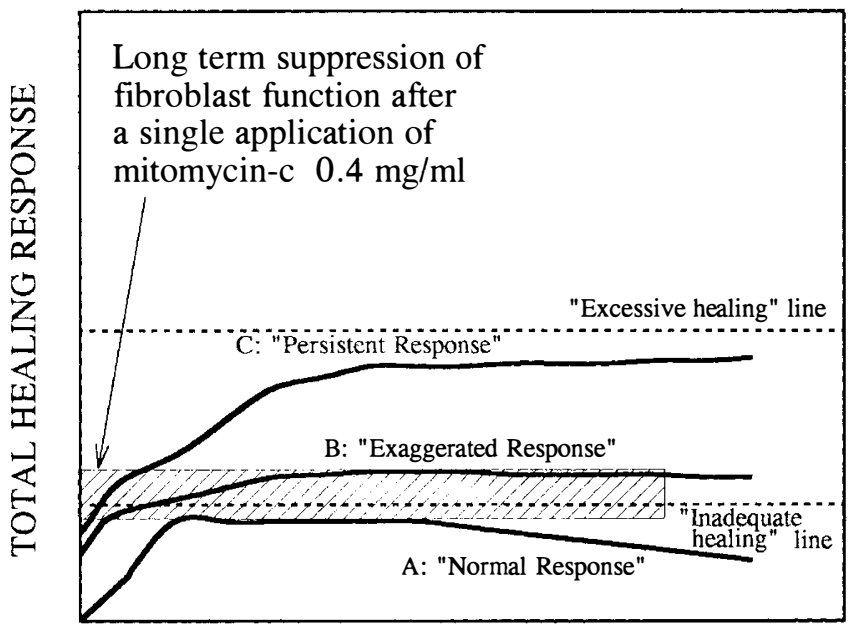

TIME AFTER INJURY

(c)

Fig. 3. (a) Different healing profiles. The 'normal' healing response (A: e.g. elderly Caucasian patient without previous topical medications) peaks then rapidly plateaus, possibly with some fall back to baseline as aqueous under the conjunctiva is associated with some bleb thinning. This occurs without crossing above an imaginary 'excessive healing' line. Neither does the healing fall below another imaginary 'inadequate healing' line, below which there may be complications such as hypotony. The 'exaggerated' healing response (B: e.g. a patient who has received chronic topical medications) starts higher initially and reaches a higher peak compared with normal. The 'persistent' response $(C$ : e.g. a patient with neovascular glaucoma and constant stimulation from the aqueous) rises to a high peak response after surgery that continues for a very prolonged period. (b) Postulated effect of a single 5 minute application of a shorter-acting agent such as 5-fluorouracil. This causes temporary suppression (weeks) and this is adequate for a 'normal' and an 'exaggerated' response, but not for higher-risk patients with a 'persistent' response who then cross the 'excessive healing' line and fail surgery. (c) Postulated effect of a single application of mitomycin- $C$. This suppresses the 'persistent' response but pushes a 'normal' response below the 'inadequate healing' line, and the 'exaggerated' response to the borderline, potentially resulting in hypotony and other complications due to inadequate healing.

We have been looking at other aspects of fibroblast function following suppression of proliferation. Another vital function of the fibroblast is its ability to contract extracellular matrix. We have been using type I collagen gels populated with ocular fibroblasts. The fibroblasts rapidly contract these collagen gels when stimulated with serum. Five-minute exposures to 5-fluorouracil and mitomycin-C also inhibit the contraction of these gels. It is of particular interest that the effects of treatment are very different depending on the state of cellular activation of the fibroblast in the gel before treatment. A 'primed' cell may respond to treatment very differently from a 'quiescent' cell, further emphasising the importance of the environment of the tissues in individual patients before and after wounding. Topical medications, the commonest form of treatment for glaucoma, have a significant effect on conjunctival cellularity, ${ }^{81}$ amount of shrinkage ${ }^{82}$ and the response to surgery. ${ }^{11}$

On a more molecular level, we have found that the 'suppressed' growth-arrested fibroblasts are still able to respond to stimulatory factors found in the wound environ- 


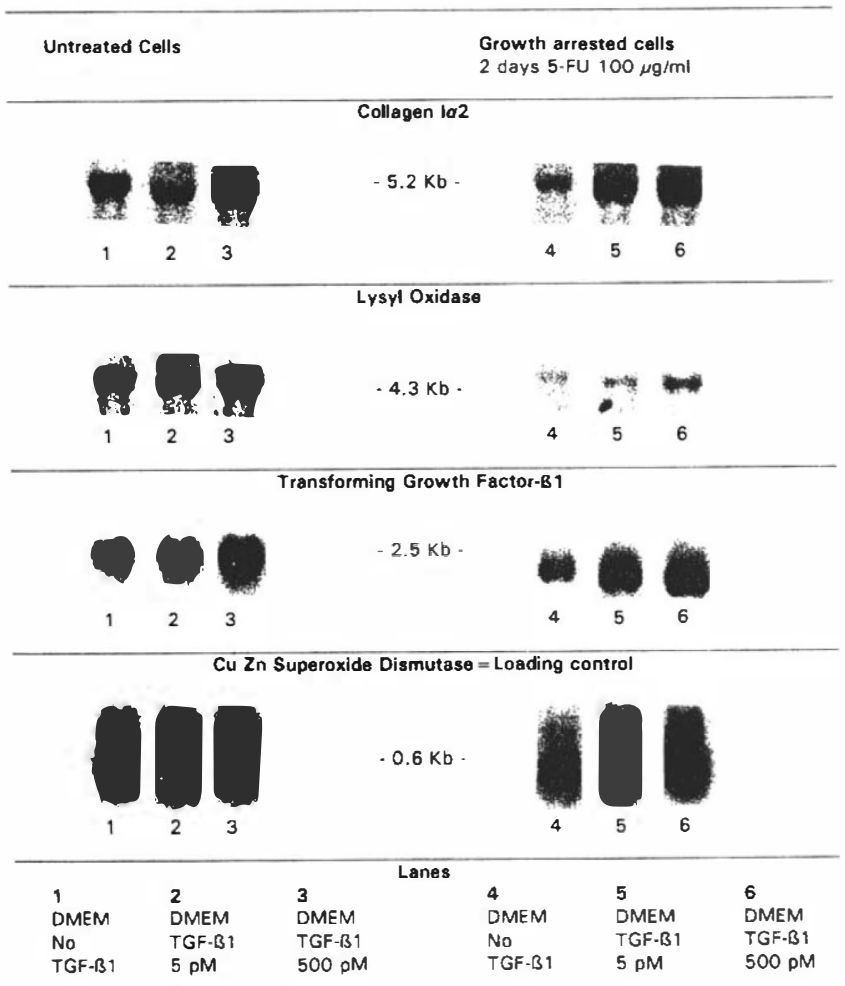

Fig. 4. Effects of transforming growth factor beta-1 (TGF- $\beta 1)$ stimulation on RNA levels of collagen, lysyl oxidase and $T G F-\beta 1$ in normal and 'growth-arrested' ocular fibroblasts. RNA levels of collagen 1 $\alpha 2$, lysyl oxidase and TGF- $\beta 1$ all showed an increase when treated with 500 pmol TGF- $\beta 1$. The cells growth arrested with 5-fluorouracil also showed relatively normal RNA levels of collagen and TGF- $\beta 1$, with an increase when stimulated with TGF- $\beta 1$. However, the levels of lysyl oxidase were markedly reduced, although there was still a response to stimulation with TGF- $\beta 1$. NB. lane 4 underloaded.

ment such as TGF- $\beta 1$. This is illustrated in Fig. 4 . We found that Tenon's capsule fibroblasts show an increase in RNA levels of collagen I $\alpha 2$ and TGF- $\beta 1$ when exposed to increasing concentrations of TGF- $\beta 1$. This has been well described in other fibroblasts. It is of interest too that the levels of lysyl oxidase are also upregulated by TGF- $\beta 1$. After the cells have been growth arrested with 5-fluorouracil, they are still able to respond to TGF- $\beta 1$ by upregulating levels of collagen I $\alpha 2$ and TGF- $\beta 1$ with slightly attenuated but nonetheless similar responses to untreated cells. It is interesting that there is a differential effect on the RNA levels of lysyl oxidase which were much lower, although there was still an increase in RNA levels with higher concentrations of TGF- $\beta 1$. So suppressed cells, although growth arrested, are still able to respond to exogenous stimulation at the level of transcription.

On the basis of these studies we have performed pilot studies in vitro on drainage blebs induced by mitomycin-C. When the blebs are injected with growth factors including TGF- $\beta 1$ a healing response is generated which begins to reverse the effects of the mitomycin-C (Fig. 5). Thick scar tissue develops surrounding the bleb and the bleb begins to opacify and shrink compared with the effect of a control injection of carrier only. We are currently investigating the cellular and molecular mechanism of this scarring. How- ever, what this pilot experiment confirms is that the effects of local suppression of fibroblasts can be significantly altered by changes in the wound environment.

In summary, we now have a variety of effective methods to suppress fibroblast function. In particular, the single exposures to antiproliferative agents are at present the most practical method of achieving fibroblast suppression after glaucoma filtration surgery. From basic research we now understand a great deal more about how these treatments work in vitro and in vivo. However, we have also shown that the state of activation of the cell, and the stimulatory factors activating the cell, can have profound effects on the healing response mediated by the 'suppressed' cells and tissues as a whole. A deeper understanding of the basic cellular and molecular biology of the healing process, variations in different individuals and circumstances and the effects of modulating agents on the fibroblast in particular are essential. With this knowledge, we may then be able to achieve totally safe but effective control of the scarring process, not just in the eye but in the whole human body.

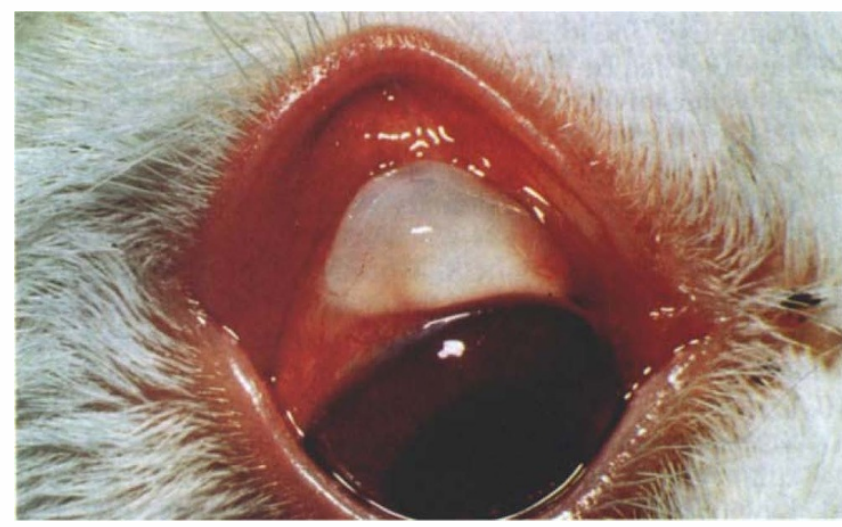

(a)

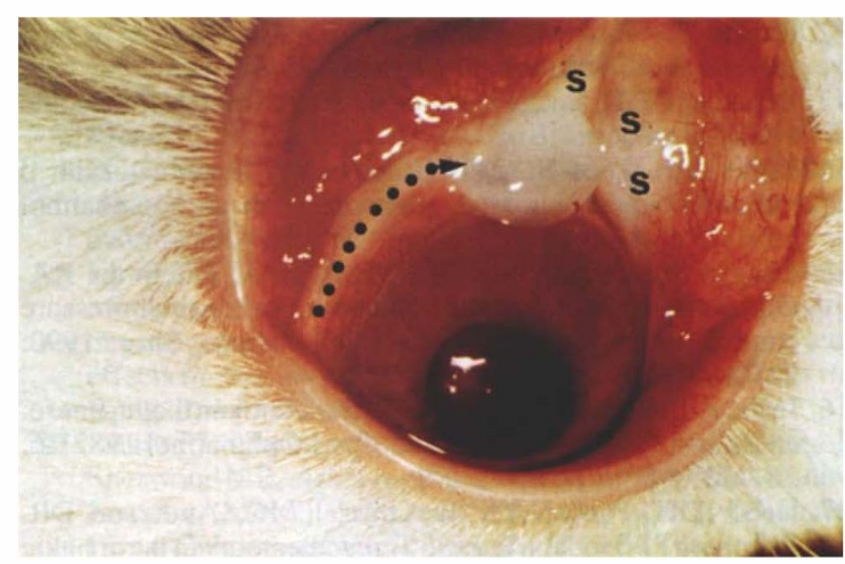

(b)

Fig. 5. Effect of exogenous growth factor (TGF- $\beta 1)$ on the area growth arrested with a single 5 minute application of mitomycin-C. (a) Rabbit eye 40 days after treatment with a 5 minute exposure to mitomycin- $C$ during experimental filtration surgery. Injection of control carrier at day 30. The bleb is still enlarged and draining. (b) Rabbit eye 40 days after treatment with a 5 minute exposure to mitomycin-C before glaucoma filtration surgery. Injected with TGF- $\beta 1 /$ carrier into bleb. The bleb has contracted from the periphery inwards. Thick subconjunctival scar tissue is present in surrounding tissue(s) including the injection track (dotted line with arrow). 
These studies were funded in part by the Wellcome Trust, the Oxford Congress Scholarship, the TFC Frost Charitable Trust, Moorfields, LORS and NIH grant EY 05587. We thank Dr Thomas Yang and Dr Harry Nick for the cDNA probes for lysyl oxidase and superoxide dismutase. We also thank Ms Vicki Scott for her expert assistance with the preparation of this paper and the illustrations.

Key words: Antiproliferative agents, Fibroblast, Growth factors, RNA, Scarring, Wound healing.

\section{REFERENCES}

1. Leske MC. The epidemiology of open-angle glaucoma. Am J Epidemiol 1983;118:166-91.

2. Foster A, Johnson GJ. Magnitude and causes of blindness in the developing world. Int Ophthalmol 1990;14:135-40.

3. Armaly MF, Krueger DE, Maunder L. Biostatistical analysis of the collaborative glaucoma study. I. Summary report of the risk factors for glaucomatous visual field defects. Arch Ophthalmol 1980;98:2163-7.

4. Sommer A. Intraocular pressure and glaucoma [Editorial]. Am J Ophthalmol 1989;107:186-8.

5. Watson PG, Grierson I. The place of trabeculectomy in the treatment of glaucoma. Ophthalmology 1981;88:175-96.

6. Jay JL. Rational choice of therapy in primary open angle glaucoma. Eye 1992;6:243-7.

7. Jay JL, Allan D. The benefit of early trabeculectomy versus conventional management in primary open angle glaucoma relative to severity of disease. Eye 1989;3:528-35.

8. Jay JL, Murray SB. Early trabeculectomy versus conventional management in primary open angle glaucoma. $\mathrm{Br} \mathbf{J}$ Ophthalmol 1988;72:881-9.

9. Hitchings RA, Migdal CS, Wormald R, Poinooswamy D, Fitzke F. The primary treatment trial. The changes in the visual field analysis by computer-assisted perimetry. Eye 1994;8:117-20.

10. Lichter PR, Becker MH, Janz NK. The case for quality of life assessment in glaucoma clinical trials. In: Krieglstein GK, editor. Glaucoma update IV. Berlin: Springer, 1991:187-92.

11. Lavin MJ, Wormald RPL, Migdal CS, Hitchings RA. The influence of prior therapy on the success of trabeculectomy. Arch Ophthalmol 1990;108:1543-8.

12. Cairns JE. Trabeculectomy: preliminary report of a new method. Am J Ophthalmol 1968;66:673-9.

13. Benedikt OP. Drainage mechanism after filtration. Glaucoma 1979;1:71-7.

14. Miller MH, Rice NSC. Trabeculectomy combined with $\beta$ radiation for congenital glaucoma. $\mathrm{Br} \mathrm{J}$ Ophthalmol 1991;75:584-90.

15. Longstaff S, Wormald RPL, Mazover A, Hitchings RA. Glaucoma triple procedures: efficacy of intraocular pressure control and visual outcome. Ophthalmic Surg 1990; 21:786-93.

16. Inaba Z. Long term results of trabeculectomy in the Japanese: an analysis of life-table method. Jpn J Ophthalmol 1982;26: 361-73.

17. Heuer DK, Parrish RK II, Gressel MG, Anderson DR, Palmberg PF, Hodapp E, et al. Trabeculectomy in the aphakic eye. Ophthalmology 1984;91:1045-51.

18. StewartRH, Kimbrough RL, Bachh H, Allbright M. Trabeculectomy and modifications of trabeculectomy. Ophthalmic Surg 1979;10:76-80.

19. Schwartz AL, Anderson DR. Trabecular surgery. Arch Ophthalmol 1974;92:134-8.

20. Sturmer J, Broadway DC, Hitchings RA. Young patient trabeculectomy: assessment of risk factors for failure. Ophthalmology 1993; 100:928-39.

21. Miller RD, Barber JC. Trabeculectomy in black patients. Ophthalmic Surg 1981;12:46-50.

22. Berson D, Landau L, Zauberman H, Blumenthal M. Filtering operations in Africans. Am J Ophthalmol 1969;67:395-8.
23. Iliff CE. Surgical control of glaucoma in the Negro. Am J Ophthalmol 1944;27:731-8.

24. Merritt JC. Filtering procedures in American blacks. Ophthalmic Surg 1980;11:91-4.

25. The fluorouracil filtering surgery study group. Fluorouracil filtering surgery study: one-year follow-up. Am J Ophthalmol 1989;108:625-35.

26. Heuer DK, Parrish RK II, Gressel MG, Hodapp E, Desjardins DC, Skuta GL, et al. 5-Fluorouracil and glaucoma filtering surgery. III. Intermediate follow-up of a pilot study. Ophthalmology 1986;93:1537-46.

27. Herschler J. The inhibitory factor in aqueous humour. Vision Res 1981;21:163.

28. Jampel HD. Ascorbic acid is cytotoxic to dividing human Tenon's capsule fibroblasts: a possible contributing factor in glaucoma filtration surgery success. Arch Ophthalmol 1990;108:1323-5.

29. Joseph JP, Grierson I, Hitchings RA. Normal rabbit aqueous humour, fibronectin and fibroblast conditioned medium are chemoattractant to Tenon's capsule fibroblasts. Eye 1987;1:585-92.

30. Joseph JP, Grierson I, Hitchings RA. Chemotactic activity of aqueous humour: a cause of failure of trabeculectomies. Arch Ophthalmol 1989;107:69-74.

31. Krause U, Niemi A, Raunio A. Effect of paracentesis on the protein content of the aqueous humour. Ophthalmologica 1971;163:136-49.

32. Snaders DR, Kraff MC, Lieberman HL. Breakdown and re-establishment of the blood-aqueous barrier with implant surgery. Arch Ophthalmol 1982;100:588-92.

33. Reddan J, Weinsieder A, Wilson D. Aqueous humour from traumatised eyes triggers cell division in the epithelia of cultured cells. Exp Eye Res 1979;28:267-76.

34. Harris AK, Stopak D, Wild P. Fibroblast traction as a mechanism for collagen morphogenesis. Nature 1981; 290:249-51

35. Ross R, Odland G. Human wound repair. II. Inflammatory cells, epithelial-mesenchymal interrelations and fibrogenesis. J Cell Biol 1968;39:152-68.

36. Miller MH, Grierson I, Unger WI, Hitchings RA. Wound healing in an animal model of glaucoma fistulising surgery in the rabbit. Ophthalmic Surg 1989;20:350-7.

37. Regan EF. Scleral cautery with iridectomy: an experimental study. Trans Am Ophthalmol Soc 1963;61:219-31.

38. Desjardins DC, Parish RK II, Folberg R, et al. Wound healing after filtering surgery in owl monkeys. Arch Ophthalmol 1986; 104:1835-9.

39. Hitchings RA, Grierson I. Clinico-pathological correlation in eyes with failed fistulising surgery. Trans Ophthalmol Soc UK 1983;103:84-8.

40. Peacock E. Wound repair. Philadelphia: Saunders, 1984: 102-40.

41. Postlethwaite AE, Synderman RK, Kang AH. Generation of a fibroblast chemotactic factor in serum by activation of complement. J Clin Invest 1979;64:1379-85.

42. Postlethwaite AE, Keski-Oja J, Moses HL, Kang AH. Stimulation of the chemotactic migration of human fibroblasts by transforming growth factor beta. J Exp Med 1987;165:251-6.

43. Postlethwaite AE, Seyer JM, Kang AH. Chemotactic attraction of human fibroblasts to type I-II-III collagens and collagen-derived peptides. Proc Natl Acad Sci USA 1978;75:871-5.

44. Postlethewaite AE, Kang AH. Collagen and collagen peptide-induced chemotaxis of human blood monocytes. J Exp Med 1976;143:1299-307.

45. Postlethwaite AE, Keski-Oja J, Balian G. Induction of fibroblast chemotaxis by fibronectin: localisation of the chemotactic region to a 140000 molecular weight nongelatin-binding fragment. J Exp Med 1981;153:494-9.

46. Albrink WS, Wallace AC. Aqueous humor as a tissue culture nutrient. Proc Soc Exp Biol Med 1951;77:754-8. 
47. Shah M, Foreman DM, Ferguson MWJ. Control of scarringin adult wounds by neutralising antibody to transforming growth factor beta. Lancet 1992;339:213-4.

48. Joseph JP, Grierson I, Hitchings RA. Taxol, cytochalasin B and colchicine effects on fibroblast migration and contraction: a role in glaucoma filtration surgery. Curr Eye Res 1989;8:203-15.

49. Jampel HD, Leong KW, Koya P, Quigley HA. The use of hydrophobic drugs incorporated into polyanhydrides in experimental glaucoma surgery. Invest Ophthalmol Vis Sci (Suppl) 1990;31:2.

50. Siegel RC. Collagen cross-linking effect of D-penicillamine on cross-linking in vivo. J Biol Chem 1977;252:254.

51. McGuigan LJB, Cook DJ, Yablonski ME. Dexamethasone, D-penicillamine, and glaucoma filtering surgery in rabbits. Invest Ophthalmol Vis Sci 1986;27:1755.

52. McGuigan LJB, Mason RP, Sanchez R, Quigley HA. D-penicillamine and beta-aminopropionitrile effects on experimental filtering surgery. Invest Ophthalmol Vis Sci 1987;28:1625-1629.

53. Moorhead LC, Stewart RH, Kimbrough PL, Gross RL, Cyrlin MN, LeBlanc RP, Shields MB, Kapetansky FN. Use of betaaminopropionitrile following glaucoma filtering surgery. Invest Ophthalmol Vis Sci (Suppl) 1990;31:3.

54. Chen DM, DiSabato G, Field L, Gallo AA, Harshman S. Some immunological effects of penicillamine. Clin Exp Immunol 1977;30:317.

55. Blumenkranz MS, Claflin A, Hajek AS. Selection of therapeutic agents for intraocular proliferative disease: cell culture evaluation. Arch Ophthalmol 1984;102:598-604.

56. Blumenkranz MS, Ophir A, Claflin AJ, Hajek A. Fluorouracil for the treatment of massive periretinal proliferation. Am J Ophthalmol 1982;94:458-67.

57. Lee DA, Shapourifar-Tehrani D, Kitada S. The effect of 5-fluorouracil and cytarabine on human fibroblasts from Tenon's capsule. Invest ophthalmol Vis Sci 1990;31:1848-55.

58. Litin BS, Herscler J. Silver staining of human aqueous humour proteins resolved by gel electrophoresis. Graefes Arch Clin Exp Ophthalmol 1984;221:290-2.

59. Schmidt JA, Mizel SB, Cohen D, Green I. Interleukin-1, a potential regulator of fibroblast proliferation. J Immunol 1982;128:2177.

60. Lee DA, Shapourifar-Tehrani S, Stephenson TR, Kitada S. The effects of the fluorinated pyrimidines FUR, FUdR, FUMP, and FdUMP on human Tenon's fibroblasts. Invest Ophthalmol Vis Sci 1991;32:2599-609.

61. Gillies M, Su T, Sarossy M, Hollows F. Interferon-alpha 2b inhibits proliferation of human Tenon's capsule fibroblasts. Graefes Arch Clin Exp Ophthalmol 1993;231:118-21.

62. Lee DA, Lee TC, Cortes AE, Kitada S. Effects of mithramycin, mitomycin, daunorubicin and bleomycin on human subconjunctival fibroblast attachment and proliferation. Invest Ophthalmol Vis Sci 1990;31:2136-44.

63. Blumenkranz MS, Hartzer MK, HajekAS. Selection of therapeutic agents for intraocular proliferative disease. II. Differing antiproliferative activity of the fluoropyrimidines. Arch Ophthalmol 1987;105:396-9.

64. Senderoff RI, Weber PA, Smith DR, Sokolski TD. Evaluation of antiproliferative agents using a cell culture model. Invest Ophthalmol Vis Sci 1990;31:2572-8.

65. Skuta GL, Assil K, Parrish RK II, Folberg R, Weinreb RN. Filtering surgery in owl monkeys treated with the antimetabolite 5-fluorouridine $5^{\prime}$-monophosphate entrapped in multivesicular liposomes [letter]. Am J Ophthalmol 1987;103: $714-5$.
66. Kay JS, Litin BS, Jones MA, Fryczkowski AW, Chvapil M, Herschler J. Delivery of antifibroblast agents as adjuncts to filtration surgery. II. Delivery of 5-fluorouracil and bleomycin in a collagen implant: pilot study in the rabbit. Ophthalmic Surg 1986; 17:796-801.

67. Sachdev S, Zou X, Higginbotham E. The effect of 5-fluorouracil impregnated collagen shield implants in filtration surgery. Invest Ophthalmol Vis Sci (Suppl) 1990;31:3.

68. Lee DA, Flores RA, Anderson PJ, Leong KW, Teekhasaenee C, De Kater AW, Hertzmark E. Glaucoma filtration surgery in rabbits using bioerodible polymers and 5-fluorouracil. Ophthalmology 1987;94:1523-30.

69. Jampel HD, Leong KW, Dunkelburger GR, Quigley HA. Glaucoma filtering surgery in monkeys using 5-fluorouridine in polyanhydride discs. Arch Ophthalmol 1990;108:430-5.

70. Winter DF, Jones MA, Simmons ST, Smith RS. A histologic analysis of 5-fluorouracil liposomal delivery system following subconjunctival injection in rabbits. Invest Ophthalmol Vis Sci (Suppl) 1987;28:271.

71. Chen C-W, Huang H-T, Bair JS, Lee C-C. Trabeculectomy with simultaneous topical application of mitomycin-C in refractory glaucoma. J Ocul Pharmacol 1990;6:175-82.

72. Chen CW. Enhanced intraocular pressure controlling effectiveness of trabeculectomy by local application of mitomycin C. Trans Asia Pacif Acad Ophthalmol 1983;9:172-7.

73. Khaw PT, Sherwood MB, MacKay SLD, Rossi MJ, Schultz GS. Five-minute treatments with fluorouracil, floxuridine, and mitomycin have long-term effects on human Tenon's capsule fibroblasts. Arch Ophthalmol 1992;110:1150-4.

74. Khaw PT, Ward S, Grierson I, Rice NSC. The effects of betaradiation on proliferating human Tenon's capsule fibroblasts. Br J Ophthalmol 1991;75:580-3.

75. Khaw PT, Ward S, Porter A, Grierson I, Hitchings RA, Rice NSC. The long-term effects of 5-fluorouracil and sodium butyrate on human Tenon's fibroblasts. Invest Ophthalmol Vis Sci 1992;33:2043-52.

76. Doyle JW, Sherwood MB, Khaw PT, McGorray S, Smith MF. Effects of different regimens of 5-fluorouracil on experimental glaucoma filtration surgery. Invest Ophthalmol Vis Sci 1993;34:3313-9.

77. Khaw PT, Doyle JW, Sherwood MB, Smith FM, McGorray S. Effects of intraoperative 5-fluorouracil or mitomycin $\mathrm{C}$ on glaucoma filtration surgery in the rabbit. Ophthalmology 1993;100:367-72.

78. Khaw PT, Doyle JW, Sherwood MB, Grierson I, Schultz GS, McGorray S. Prolonged localised tissue effects from 5-minute exposures to fluorouracil and mitomycin C. Arch Ophthalmol 1993;111:263-7.

79. Khaw PT, Sherwood MB, Doyle JW, Smith MF, Grieson I, McGorray S, Schultz GS. Intraoperative and post-operative treatment with 5-fluorouracil and mitomycin-C: long term effects in vivo on subconjunctival and scleral fibroblasts. Int Ophthalmol 1992;16:381-5.

80. Khaw PT, Mannan M, Vyas W, Alexander R, Jefferies L, Sherwood MB, et al. Single intraoperative exposures to mitomycin c (MMC): long term effects on scleral cellularity. Invest Ophthalmol Vis Sci (Suppl) 1993;34:726.

81. Sherwood MB, Grierson I, Millar L, Hitchings RA. Longterm morphologic effects of antiglaucoma drugs on the conjunctiva and Tenon's capsule in glaucomatous patients. Ophthalmology 1989;96:327-35.

82. Schwab IR, Linberg JV, Gioia VM, Benson WH, Chao GM. Foreshortening of the inferior conjunctival fornix associated with chronic glaucoma medications. Ophthalmology 1992; 99:197-202. 